\title{
Análisis del contenido científico de la publicidad en la prensa escrita
}

\author{
Ángel Ezquerra Martínez ${ }^{1}$ y Belén Fernández-Sánchez ${ }^{2}$ \\ Dpto. Didáctica Ciencias Experimentales. Facultad de Educación. Universidad Complutense Madrid. \\ 1'angel.ezquerra@edu.ucm.es, ${ }^{2}$ belenfersan@gmail.com.
}

[Recibido en diciembre de 2013, aceptado en marzo de 2014]

\begin{abstract}
En este artículo se realiza un análisis del contenido científico de la publicidad que se encuentra en la prensa escrita. El análisis llevado a cabo desvela la existencia de contenidos de carácter científico en los distintos componentes de los mensajes publicitarios. Además, se han recogido los tipos de utilización que se hace de la ciencia y se han observado algunos cambios en los temas tratados en los últimos años. Todo esto nos hace pensar que la publicidad puede considerarse como un indicador de las tendencias de los temas sociocientíficos que reciben los individuos. En este sentido, los estudios sobre los medios de comunicación de masa y su publicidad resultan una fuente de la que extraer referentes que, queramos o no, afectan a nuestra ciudadanía. Por todo esto, parece pertinente su análisis desde el punto de vista de la didáctica de las ciencias experimentales. Asimismo, se han considerado las características de su posible utilización en el aula.
\end{abstract}

Palabras clave: alfabetización científica; ciencia y publicidad; cuestiones sociocientíficas; prensa escrita; formación del ciudadano.

\section{Analysis of scientific content of advertising in the press}

In this paper we analyse the scientific content of the publicity in the press. The analysis shows the existence of scientific content in the various components of advertising messages. In addition, we have collected the types of use made of science and there have been some changes in the topics covered in recent years. All this makes us believe that advertising can be seen as an indicator of trends in socioscientific issues that individuals receive. Thereby, studies on media and advertising are a source from which to draw references that affect citizenship. Because of this, it seems relevant its analysis from the point of view of experimental science teachings. Additionally, we have considered the characteristics of their possible implementation in the classroom.

Keywords: scientific literacy; science and advertising; socioscientific issues; press; citizenship education.

\section{Introducción}

Nuestra sociedad es una sociedad de consumo, todo lo que nos rodea nos incita, de una forma u otra, a consumir algún tipo de bien, servicio o producto. La publicidad, transmitida a través de los medios de comunicación de masa (MCM), es uno de los agentes que, según Osuna (2008), ha tenido una mayor influencia a la hora de potenciar el consumismo entre la ciudadanía. Esta tendencia se ha ido incrementando desde mediados del siglo pasado, donde el consumo pasó de cubrir las necesidades básicas de cada persona a satisfacer pretensiones secundarias, más superfluas y creadas por las estrategias de marketing. Por esta razón y tal y como afirma Río (1986), la educación actual juega - o debería jugar- un papel decisivo en las sociedades basadas en el consumo; debería tener, entre otras finalidades, la de dotar a los futuros ciudadanos y ciudadanas de herramientas que les permitan ser críticos sobre las decisiones que deben tomar.

Por otra parte, en las últimas décadas, la importancia de la ciencia en el día a día y la preocupación de la ciudadanía por sus consecuencias sociales han ido aumentando. Esto se ve reflejado en las encuestas sobre percepción social de la ciencia y la tecnología que el FECYT lleva realizando desde el año 2002. En el último estudio, llevado a cabo en el año 2010, se recoge un incremento de un 36,5\% en el interés que los ciudadanos manifiestan de forma espontánea hacia la ciencia y la tecnología con respecto al año 2008. Por otro lado, los tópicos 
relacionados con medicina y salud, alimentación y consumo y, medio ambiente y ecología ocupan el primer, tercer y cuarto lugar respectivamente de la lista sobre los temas que más interesan (FECYT, 2011).

Esto implica que los ciudadanos perciben la importancia de determinados tópicos científicos y tecnológicos - y los valoran, lo que parece indicar que existe una demanda de lo que en términos didácticos se ha definido como alfabetización científica. En este sentido, creemos que los ciudadanos necesitamos una formación científica, diferente a la propedéutica, que nos permita comprender la ciencia y la tecnología que se nos presenta en distintas situaciones de nuestro día a día, así como valorar los cambios que se producen a lo largo de nuestra vida (Linn, 2002; Pro y Ezquerra, 2004; Vázquez y Manassero, 2007). Esta formación nos debería capacitar para tomar decisiones relacionadas con nuestro bienestar personal, el bienestar social y el bienestar del medio ambiente (Harlen, 2001). Esto implica poder realizar, de manera autónoma, una serie de acciones destinadas a dar respuesta a las numerosas situaciones que nos van a surgir en nuestro día a día (Hogan, 2002; Kolstø, 2006; Lewis y Leach, 2006). Estas situaciones se pueden concretar, entre otras, en los siguientes casos:

- La ciencia presente en los medios de comunicación de masas. Los MCM determinan parte de la percepción social que el ciudadano tiene sobre los tópicos de interés (O’Sullivan, Dutton y Rayner, 1998; Ezquerra, 2003). Por esta razón, su análisis supone una línea de estudio sobre qué ciencia hay en la sociedad (Pro y Ezquerra, 2005; Ezquerra, 2007). Así, podemos encontrar la ciencia que aparece en las noticias de impacto mediático (Jiménez-Liso, Hernández y Lapetina, 2010; Esteban y PérezEsteban, 2012) la que se encuentra en los espacios meteorológicos (Ezquerra y Pro, 2006), la ciencia que aparece en los espacios televisivos generales (Ezquerra y Polo, 2010), en algunas series de televisión (Perales y Vílchez, 2002; García Borrás, 2005; García Borrás, 2008), en las revistas de divulgación, en las secciones de ciencia de la prensa escrita (Halkia y Mantzouridis 2005; Jarman y McClune, 2007), en los programas de radio, etc.

- La ciencia presente en los procesos de compra. Una de las acciones más habituales en el quehacer diario humano es la recolección de recursos para el día a día. En otras sociedades, estas labores estaban ligadas a la agricultura, la pesca, la caza o la recolección. En nuestra sociedad, los ciudadanos llevamos a cabo esta tarea, fundamentalmente, bajo el apelativo de proceso de compra. Resulta posible dividir esta labor en varios pasos que tienen diferente vinculación con la ciencia y la tecnología: cuando se interacciona con la publicidad (Jiménez-Liso, Torres, Salinas y González, 2000; Campanario, Moya y Otero, 2001), cuando nos informamos con, por ejemplo, las etiquetas de los productos (Ezquerra, Fernández-Sánchez y Cabezas, 2013), al tener que tomar decisiones en las que hay implicada información científica o técnica, etc.

- La ciencia de los alimentos y el consumo. Si bien este contenido está relacionado con el anterior, es de tal magnitud que requiere un epígrafe aparte. Esto es debido a que cada vez son más los productos funcionales que salen al mercado y el porcentaje de la población que los consume. Por otro lado, existe un temor o una desconfianza generalizada hacia, por ejemplo, los alimentos transgénicos, así como una preferencia hacia lo natural frente a lo químico (bien es cierto que todo, incluido los productos naturales, contiene química). Del mismo modo parece que se identifica lo natural con lo no químico y sano mientras que lo artificial, con lo químico y perjudicial para la salud (López Nicolás, 2013). 
- La ciencia presente en los programas políticos. Todos los programas electorales de los partidos más votados en las últimas elecciones generales celebradas en España en noviembre de 2011, cuentan con puntos sobre ciencia y tecnología, entre otros: lucha contra el cambio climático; biodiversidad y protección litoral; ciencia y tecnología (Programa Electoral PSOE, 2011); nuevas fronteras para la ciencia y el conocimiento; respetuosos con el medio ambiente (Programa Electoral PP, 2011); propuestas sobre transporte sostenible y modelo energético (Programa Electoral IU-Los Verdes, 2011); medio ambiente y gestión del territorio (Programa Electoral UPyD, 2011).

- La ciencia relacionada con la medicina y la salud. Como ya se ha comentado, en la última encuesta realizada por el FECYT sobre percepción social de la ciencia y la tecnología se indica que este tópico es el que despierta un mayor interés entre la población (FECYT, 2011).

- La ciencia implícita en el respeto por el medio ambiente, la ecología y el desarrollo sostenible.

La respuesta a estas cuestiones y otras más, conlleva un conjunto de pasos que todos llevamos a cabo en nuestro quehacer diario cada vez que debemos tomar una decisión sobre una cuestión que lleva implícita información científica o tecnológica:

1. Plantearse como algo de interés para uno mismo una cuestión con connotaciones científico-tecnológicas (p.e., ¿qué consecuencias para la sociedad y para el país puede tener que se recorte en investigación? (de los debates políticos); ¿en qué consiste el fracking y cuáles son sus consecuencias? (de las noticias de impacto en los medios de comunicación); ¿son los conservantes de los alimentos tan perjudiciales como nos hacen creer? (de la preocupación por la salud y la alimentación); zes capaz una crema de reactivar de manera inteligente la vida de las células? (de la publicidad).

2. Determinar cuál es la información que se necesita.

3. Seleccionar entre las posibles fuentes de información y acceder a ellas.

4. Realizar la búsqueda correspondiente.

5. Comprender los contenidos a los que se está teniendo acceso para ser capaz de solucionar las dudas y dificultades.

6. Ser crítico con dichos contenidos.

7. Responder a las preguntas planteadas inicialmente.

En los últimos años, la respuesta a esta demanda ciudadana ha venido dada, entre otros, desde la administración (a través de diferentes planteamientos desarrollados en los currículos escolares), desde los equipos de investigación (planificando nuevas líneas de investigación) y desde la comunidad educativa (poniendo en práctica diferentes enfoques innovadores de la enseñanza centrados en las necesidades del ciudadano).

De modo muy resumido, indicamos que en la LOGSE, vigente desde 1990 hasta 2006, ya se incluían una serie de principios, intenciones y objetivos generales destinados a contextualizar la enseñanza de las ciencias (Oliva y Acevedo, 2005), aunque bien es cierto que aquí, todavía, se pone de manifiesto el enfoque propedéutico de la enseñanza de las ciencias (RD 1345/1991:40). La LOE, puesta en vigor en el año 2006, incorpora una serie de referencias sobre la importancia de la ciencia como parte de la cultura básica y la significación de la educación científica para la formación de ciudadanos. Además, incluye nuevos aspectos relacionados con la importancia del enfoque CTS y la adquisición de las competencias básicas (RD 1631/2006). Se intenta fomentar, de este modo, una percepción más positiva hacia la 
ciencia, así como una visión más completa del conocimiento científico (APICE, 2007; Mas, Hernández, Solbes y Vilches, 2007).

Desde la comunidad educativa (equipos de investigación y docentes), han surgido diversos movimientos destinados a aportar nuevos enfoques para la enseñanza de las ciencias, caracterizados por emblemas como ciencia para la ciudadanía, ciencia tecnología y sociedad (CTS) o alfabetización cientifica y tecnológica (Acevedo, Manassero y Vázquez, 2002) y nuevas investigaciones sobre cuestiones sociocientíficas-socioscientific issues- (Zeidler, Sadler, Simmons y Howes, 2005). Son numerosos los profesionales que trabajan en esta línea, contextualizando los contenidos que se trabajan en clase mediante experiencias educativas que conectan la realidad ciudadana con los currículos escolares (Bueno, 2004; Paixão, 2004; Vázquez González, 2004; Tomás y Hurtado, 2012), entre otros, así como reflexionando sobre los principios y objetivos de la educación (Acevedo, 2004; Lemke, 2006; Banet, 2007).

Pero, a pesar de los esfuerzos que se están realizando desde hace décadas para conseguir una sociedad científicamente alfabetizada, la realidad muestra que la situación es bastante precaria y presenta importantes carencias (Marco-Stiefel, Ibáñez y Albero, 2000; Fernández-Sánchez, Ezquerra y Arillo, 2013). Por un lado, las reformas curriculares que se han llevado a cabo desde la administración no han sido efectivas. Según Caamaño (2007), el currículo actual no prepara al alumnado para que sea capaz de comprender los temas científicos y tome una postura crítica sobre cuestiones tecnocientíficas, de forma que considera que muchos de los contenidos de las materias de ciencias son perfectamente prescindibles. Por otra parte, Membiela (2001) afirma que los contenidos de los proyectos curriculares no se corresponden, generalmente, con su puesta en práctica por parte del profesorado.

En definitiva, nos encontramos con que el sistema actual de enseñanza de las ciencias está aún demasiado alejado del enfoque CTS que se pretende alcanzar (Hodson, 2003; Acevedo, Vázquez y Manassero, 2005). Como consecuencia, los y las estudiantes de nuestro sistema educativo no obtienen un nivel básico de la llamada alfabetización científica, siendo incapaces de utilizar un razonamiento científico que les permita comprender los fenómenos que les afectan en su día a día, y tomar decisiones reflexivas y provechosas para sus intereses. En este sentido, numerosos trabajos (Duggan y Gott, 2002; Jiménez-Liso, Sánchez y De Manuel, 2001; Pozo y Gómez Crespo, 1998) coinciden en señalar la falta de conexión entre los contenidos que se dan en el aula y la vida cotidiana de nuestro alumnado.A pesar de las propuestas de diversos autores (Membiela, 2002; Gómez Crespo, Gutiérrez y Martín-Díaz, 2005; MarcoStiefel, 2007), entre otros, no existen unos referentes claros que nos indiquen qué conocimientos debe tener una persona para encontrarse científicamente alfabetizada.

En base a estos planteamientos, nuestra línea de investigación se dirige a analizar cuáles son los conocimientos que, desde un punto de vista científico, un ciudadano medio necesita a la hora de interaccionar socialmente. En cierto sentido, esta labor debería proporcionar un conjunto de referentes que nos indiquen qué conocimientos debería tener una persona científicamente alfabetizada. Sin embargo, somos conscientes de la dificultad que supone esta tarea, debido, sobre todo, a la inmensa cantidad de contenidos que esto puede abarcar. En este trabajo centramos nuestro objetivo en analizar la ciencia que aparece en la publicidad, el modo en que lo hace, las consecuencias sobre la ciudadanía y las posibles aplicaciones en el aula de este referente sociocientífico.

No resulta difícil encontrar que, con mucha frecuencia, la ciencia aparece de un modo u otro en la publicidad. Aun así, son pocos los estudios que, hasta la fecha, ponen de manifiesto esta relación. Esta afirmación deriva de la revisión llevada a cabo en cinco revistas españolas de didáctica de las ciencias y comunicación educativa desde el año 2000 hasta la actualidad (Enseñanza de las Ciencias, Revista Electrónica de Enseñanza de las Ciencias, Alambique, Revista Eureka 
sobre Enseñanza y Divulgación de las Ciencias, y Comunicar), en la que solo se han encontrado tres artículos sobre este tópico (Jiménez-Liso et al., 2000; Campanario et al., 2001; Moreno, 2006).

Existen otros trabajos en publicaciones más centradas en la comunicación y la publicidad. Un ejemplo es el trabajo realizado por Medina i Cambrón, Sorribas y Ballano (2007), en la que se analiza, desde un punto de vista teórico, la relación entre publicidad y ciencia.

\section{Metodología}

Para llevar a cabo este estudio sobre la ciencia que hay en la publicidad hemos diseñado el siguiente protocolo de análisis. En primer lugar, elegimos el soporte donde analizaríamos los anuncios. Los medios de comunicación son muy variados: diarios, suplementos, revistas, radio, televisión, internet... En este trabajo hemos optado por la prensa escrita ya que, además de ocupar el tercer puesto en inversión publicitaria entre los medios convencionales, superado únicamente por la televisión e internet (Estudio Info Adex, 2013), dispone de un registro permanente de los contenidos a través de las hemerotecas, algo que no sucede con los dos primeros.

Para seleccionar los diarios sobre los que íbamos a llevar a cabo nuestro análisis, tuvimos en cuenta cuáles eran los periódicos de información general en castellano con mayor tirada a nivel nacional. Estos resultaron ser El País, El Mundo, ABC y 20 Minutos (EGM, 2012).

Una vez determinados los periódicos, proseguimos con la elección de los números que íbamos a analizar. Para ello, dado que se pretendía evitar que el estudio estuviese afectado por variables estacionales a lo largo del tiempo y siguiendo los dictados de las técnicas de análisis (Hernández, Fernández y Baptista, 2010), se decidió abarcar un periodo amplio de tiempo y seleccionar distintos días de la semana, evitando de este modo un mismo tipo. Así, elegimos aleatoriamente un día del mes, que barre los distintos días de la semana, y analizamos todos los anuncios que aparecieron el día 7 de cada mes durante el año 2009. El hecho de analizar los diarios del año 2009 se debió a que, actualmente, la Biblioteca Nacional sólo tiene digitalizado hasta ese año. En cualquier caso, llevamos a cabo una comparación inicial con los números del 2013 en los mismos periódicos y comprobamos que no existían diferencias apreciables entre los periódicos de ambos años.

Escogidos los periódicos (El País, El Mundo, ABC y 20 Minutos) y los números donde íbamos a buscar (días 7 de cada mes de 2009), analizamos todos los anuncios que encontramos (un total de 718), con el fin de determinar si contenían ciencia o no. Consideramos que un anuncio aludía a esta temática si incluía, en cualquiera de sus apartados, alguna unidad de información que contuviese alguno de los siguientes términos: magnitudes y unidades (gramos, kilómetros, voltios...); terminología científica o técnica (potencia, energía, principio activo, antioxidante...); materiales o procedimientos (faros de xenón, batería de iones de litio, bajo consumo, oxidación de proteínas...) e imágenes que sugirieran ciencia (foto de científico, estructuras moleculares...). De este modo, encontramos 139 anuncios que contenían algún tipo de alusión a la ciencia o tecnología.

Una vez aisladas las unidades de información con contenido científico o técnico se procedió a su agrupación en categorías excluyentes. En parte, estas estaban preestablecidas (magnitudes, unidades, terminología científica) y, en parte, resultaron emergentes de los elementos analizados (materiales, procedimientos e imágenes que sugirieran ciencia).

El último paso de nuestro método de análisis fue buscar criterios sobre cómo se estructuraba el mensaje. De este modo pudimos identificar que, para nuestros intereses, los anuncios en 
prensa están formados por tres componentes que convenimos en llamar: letra pequeña, texto publicitario e imagen publicitaria.

\section{Resultados}

Como ya hemos comentado, el primer paso fue determinar qué tipos de productos muestran en su publicidad en prensa una vinculación con la ciencia o la tecnología. El resultado fue de 139 anuncios entre los 718 encontrados. En la Tabla 1 se recogen los productos detectados y la frecuencia relativa con la que estos bienes presentan referencias tecnocientíficas en sus anuncios.

Tabla 1. Tipos de producto y presencia de ciencia y tecnología en su publicidad.

\begin{tabular}{|c|c|c|c|c|}
\hline \multirow[b]{2}{*}{ Producto que se anuncia } & \multicolumn{4}{|c|}{ Contiene ciencia } \\
\hline & $\begin{array}{l}\text { Frecuentemente } \\
\qquad(>66 \%)\end{array}$ & $\begin{array}{l}\text { A veces } \\
(33-66 \%)\end{array}$ & $\begin{array}{l}\text { Raramente } \\
(<33 \%)\end{array}$ & Nunca \\
\hline Automóvil & $\mathrm{X}$ & & & \\
\hline $\begin{array}{c}\text { Electrodomésticos (frigoríficos, lavadoras, hornos, } \\
\text { lavavajillas) }\end{array}$ & $\mathrm{X}$ & & & \\
\hline Informática & $\mathrm{X}$ & & & \\
\hline Fotografía & $\mathrm{X}$ & & & \\
\hline Televisiones & & $\mathrm{X}$ & & \\
\hline Compañías telefónicas, móviles e internet & & $\mathrm{X}$ & & \\
\hline Compañías eléctricas & $\mathrm{X}$ & & & \\
\hline Cosméticos & $\bar{X}$ & & & \\
\hline Hospitales/clínicas/asociaciones médicas & $\bar{X}$ & & & \\
\hline Ropa y calzado & & & $\mathrm{X}$ & \\
\hline Bancos y aseguradoras & & & $\mathrm{X}$ & \\
\hline Cursos, colegios y univ.privadas, convenciones... & & & & $\bar{X}$ \\
\hline Turismo (hoteles, viajes, compañías de vuelo...) & & & & $\bar{X}$ \\
\hline $\begin{array}{l}\text { Entretenimiento (televisión de pago, programas } \\
\text { tv, espectáculos, emisoras de radio, juegos de azar) }\end{array}$ & & & & $\mathrm{X}$ \\
\hline Viviendas e inmobiliarias. & & & & $\mathrm{X}$ \\
\hline Otros (supermercados, DGT, Renfe, ONGs...) & & & & $\bar{X}$ \\
\hline
\end{tabular}

Un hecho que nos llamó la atención es que no detectamos ningún anuncio de instituciones educativas — colegios privados - que hiciera referencia a la ciencia, por ejemplo, mostrando un laboratorio entre sus instalaciones. Nos preguntamos si este factor podría considerarse como un indicador sobre la —escasa - importancia que se está dando a la educación científica. Del mismo modo, tampoco encontramos alusiones científico-técnicas en anuncios sobre viviendas ni transportes y, muy pocas, en ropa y calzado.

Una vez recogidos los productos en los que aparece ciencia o tecnología entre alguno de los componentes de su mensaje publicitario, se procedió a considerar el contenido científico en cada uno de los componentes que conforman el anuncio (letra pequeña, texto publicitario e imagen publicitaria). 
Hemos observado que las unidades de información que aparece en esta categoría-letra pequeña-hacen alusión a diferentes contenidos científicos. Entre ellos cabe destacar el tipo de magnitudes utilizadas, laterminología específicamás habitual y los materiales y procedimientos más cercanos al producto comercializado. Dicha información varía en función del tipo de mercancía pero, dentro de cada grupo, y por razones legislativas (RD 1468/1988; RD 837/2002; RD 944/2010), presenta un contenido bastante homogéneo que aporta una información objetiva de las propiedades y características del producto. En definitiva, se trata de una información estandarizada y muy estable, lo que implica que sus contenidos sean predecibles y de fácil categorización. En la Tabla 2 se recogen algunos ejemplos de letra pequeña encontrada de los anuncios analizados.

Tabla 2. Letra pequeña de los anuncios analizados.

\begin{tabular}{|c|c|}
\hline Productos & Contenidos científicos \\
\hline \multirow{3}{*}{ Automóvil } & $\begin{array}{l}\text { Magnitudes: cv, diferencia de potencial [V], consumo de combustible }[1 / 100 \mathrm{~km}] \text {, emisiones } \\
\mathrm{CO}_{2}[\mathrm{~g} / \mathrm{km}] \text {, llantas de } \mathrm{xx} " \ldots\end{array}$ \\
\hline & $\begin{array}{l}\text { Terminología específica: motor gasolina o diesel, cdti, TDI, motor eléctrico, radio, MP3, CD, } \\
\text { navegador GPS, ordenador de a bordo, faros antiniebla, radioteléfono GSM... }\end{array}$ \\
\hline & Materiales: faros de xenón, llantas de aleación, baterías de iones de litio... \\
\hline \multirow{3}{*}{ Tecnología } & $\begin{array}{l}\text { Magnitudes: pulgadas, megapíxeles, tráfico de datos [Gigabits, Megabits], velocidad de } \\
\text { descarga }[\mathrm{kbit} / \mathrm{s}] \text {, masa }[\mathrm{kg}] \text {, autonomía de la batería }[\mathrm{h}] \text {, r.p.m., potencia }[\mathrm{kW}] \ldots\end{array}$ \\
\hline & $\begin{array}{l}\text { Terminología específica: módem USB, radio FM, bluetooth, ADSL, MP3, wifi, GPS, display } \\
\text { digital, eficiencia energética, procesador, memoria... }\end{array}$ \\
\hline & Materiales: Plasma, LCD \\
\hline \multirow{2}{*}{$\begin{array}{l}\text { Hospital- } \\
\text { clínicas }\end{array}$} & $\begin{array}{l}\text { Procedimientos: lifting, balón intragástrico, rinoplastia, liposucción ultrasónica, microimplante } \\
\text { de cabello, vía oral... }\end{array}$ \\
\hline & $\begin{array}{l}\text { Terminología específica: varices, reuma contracturas, tendinitis... diabetes, hipertensión, } \\
\text { osteoporosis... cirugía, medicamentos, fármacos, metabolismo, reuma, inmune, riego bascular. }\end{array}$ \\
\hline
\end{tabular}

\section{Texto publicitario}

Al analizar el texto publicitario observamos que existía una gran dispersión, tanto de los contenidos científicos utilizados, como del modo en que estos eran tratados.

El análisis de este elemento de los reclamos publicitarios en prensa nos permitió, tal y como apuntan algunos autores (Medina i Cambrón et al., 2007; Jiménez-Liso et al., 2000), detectar multitud de mensajes publicitarios que hacen un uso inadecuado de la ciencia. Siguiendo la clasificación de Campanario et al. (2001), nos hemos encontrados con mensajes que utilizan conceptos supuestamente científicos que no existen, conceptos científicos utilizados de manera inadecuada, exageraciones incorrectas, comparaciones cuantitativas incompletas, razonamientos erróneos y argumentaciones falaces o difíciles de entender. En esta línea, nosotros también hemos encontrado otra categoría a unir a las anteriores: la de aquellos anuncios que hacen un uso ilegítimo de lo ecológico y lo verde. Parece que estas afirmaciones infundadas sobre los beneficios para el medio natural del producto publicitado no eran tan habituales hace dos décadas.

Por otra parte, y siguiendo la ordenación de Gallego (2007), parece que las afirmaciones que hacen un uso inadecuado de la ciencia derivan de una imagen exclusivamente empirista $y$ ateórica, rígida (en el sentido de algorítmica, exacta e infalible), aproblemática y abistórica (ergo 
dogmática y cerrada) y excesivamente individualista (asociada a un elitismo intelectual descontextualizado).

En la Tabla 3 se muestran varios ejemplos que hacen un uso inadecuado del vocabulario científico. Aunque no son exclusivos, la mayoría de estos mensajes que utilizan ilegítimamente términos científicos se da en cosméticos y automoción, si bien es cierto que en ropa y calzado también se advierten estas prácticas.

Tabla 3. Ejemplos de anuncios que hacen un uso inadecuado del vocabulario científico.

\begin{tabular}{|c|l|}
\hline Producto & \multicolumn{1}{c|}{ Mensaje publicitario } \\
\hline \multirow{3}{*}{ Automóvil } & ...ahora la felicidad se mide en km. [Errores en el uso de conceptos científicos] \\
\cline { 2 - 3 } & La berlina de lujo más eficiente del mundo. [Exageración incorrecta] \\
\hline \multirow{5}{*}{ Cosmético } & $\begin{array}{l}\text { Elixir de juventud; energía celular e inyección de nutrientes. [Concepto inexistente } \\
\text { supuestamente científico] }\end{array}$ \\
\cline { 2 - 3 } & $\begin{array}{l}\text { Energía muscular aplicada a la derrota del paso del tiempo. [Concepto inexistente } \\
\text { supuestamente científico] }\end{array}$ \\
\cline { 2 - 3 } Ropa y calzado & $\begin{array}{l}\text { Reduce la celulitis rebelde en 4 semanas. [Concepto inexistente supuestamente científico] } \\
\text { científico] }\end{array}$ \\
\cline { 2 - 3 } & (Marca del producto). Respira. [Afirmación incorrecta desde el punto de vista científico] \\
\cline { 2 - 3 } & Nuestras zapatillas rinden un 20\% más. [Comparación cuantitativa incompleta] \\
\hline
\end{tabular}

También son muchos los mensajes que recurren a la ciencia y a la investigación como una fuente de autoridad fiable y precisa que asegura la calidad del producto que se anuncia. Según nuestros datos, son los reclamos de hospitales y clínicas los que más acuden a este tipo de fórmulas que muestran una imagen rígida de la ciencia (en el sentido de infalible). La Tabla 4 recoge algunos ejemplos al respecto.

Tabla 4. Anuncios cuyo mensaje publicitario hacen alusión a la ciencia y a la tecnología como fuente de autoridad.

\begin{tabular}{|c|l|}
\hline Producto & \multicolumn{1}{|c|}{ Mensaje publicitario } \\
\hline Clínica & $\begin{array}{l}\text { Insomnio. Estamos realizando un estudio para su tratamiento.[Empirista y } \\
\text { ateórica, rígida] }\end{array}$ \\
\hline Óptica & Tecnología experta.[Aproblemática y ahistórica] \\
\hline $\begin{array}{c}\text { Grupo } \\
\text { Hospitales }\end{array}$ & $\begin{array}{l}\text { Profesionales, tecnología e investigación más cerca de los pacientes. } \\
\text { [Empirista y ateórica, rígida] }\end{array}$ \\
\hline $\begin{array}{c}\text { Clínica } \\
\text { dental }\end{array}$ & $\begin{array}{l}\text { La cirugía virtual por ordenador lo hace posible.[Aproblemática y } \\
\text { ahistórica] }\end{array}$ \\
\hline $\begin{array}{c}\text { Instituto } \\
\text { Médico }\end{array}$ & $\begin{array}{l}\text { Estudio genético de enfermedades y factores de riesgo. [Empirista y } \\
\text { ateórica, rígida] }\end{array}$ \\
\hline
\end{tabular}

Los productos cuyos mensajes publicitarios aluden con mayor frecuencia al respeto por el medio ambiente entre los analizados en nuestra muestra de anuncios son los coches, los electrodomésticos y las compañías eléctricas. En la Tabla 5 se recogen algunos ejemplos, 
donde se puede observar que lo ecológico y el medio ambiente es utilizado como reclamo publicitario. En todos ellos se observa un enfoque aproblemático y ahistórico.

Tabla 5. Ejemplos de anuncios que aluden al medio ambiente o a lo ecológico.

\begin{tabular}{|c|l|}
\hline Producto & \multicolumn{1}{|c|}{ Mensaje publicitario } \\
\hline \multirow{2}{*}{ Automóvil } & Potencia y ecología. \\
\cline { 2 - 2 } & (...) Menos emisiones. Mejores prestaciones. \\
\cline { 2 - 2 } & El híbrido con panel solar. \\
\hline \multirow{2}{*}{ Electrodoméstico } & Electrodomésticos de bajo consumo. \\
\cline { 2 - 2 } & Consumen hasta un $20 \%$ menos que la clase A . \\
\hline Compañía eléctrica & Energía $100 \%$ renovable. \\
\hline
\end{tabular}

Obviamente, aquí solo mostramos algunos ejemplos, pero resultaría muy sencillo listar multitud de casos que recorrerían todas las categorías que hemos comentado. En cualquier caso es interesante tener presente que son muy frecuentes estos usos, ya que el porcentaje de anuncios analizados cuyo mensaje hace un mal uso de la ciencia supera el $50 \%$. No resulta difícil asumir, por tanto, que la imagen proyectada por la publicidad hacia la sociedad habla, mayoritariamente, de una ciencia estereotipada y encorsetada en unos términos —unas categorías - que distorsionan la realidad del trabajo de los científicos.

\section{Imagen publicitaria}

Este componente de los anuncios en prensa muestra una notable similitud con el elemento texto publicitario en el tipo de mensaje que pretenden transmitir. Parece que la función de ambos componentes del anuncio es la de apoyarse mutuamente, subrayando y complementando la idea que se quiere mostrar. Por tanto, resulta obvio indicar que las imágenes incurren en los mismos usos inadecuados de la ciencia-utilizando imágenes de científicos como fuente de autoridad, exagerando los efectos de secado de unos neumáticos que eliminan el agua del asfalto al paso del vehículo- o mostrando imágenes descontextualizadas y elitista de los laboratorios de investigación.

En este elemento de los anuncios, también hemos podido identificar imágenes sobre la ciencia que muestran alusiones al respeto por el medio ambiente, fundamentalmente, en los electrodomésticos y las compañías eléctricas. En la Tabla 6 se muestran algunos ejemplos.

Tabla 6. Imágenes de anuncios que aluden al respeto por el medio ambiente.

\begin{tabular}{|c|l|}
\hline \multicolumn{1}{|c|}{ Producto } & \multicolumn{1}{c|}{ Imagen } \\
\hline Compañía eléctrica & $\begin{array}{l}\text { Molinos de viento y hoja verde sobre la que se encuentra escrito el mensaje "energía } \\
\text { comprometida". }\end{array}$ \\
\hline Electrodomésticos & Frigorífico con puerta abierta sobre un fondo de paisaje verde con molinos de viento. \\
\hline Compañía eléctrica & $\begin{array}{l}\text { Chica corriendo por un bosque entre árboles muy altos a los que solo se les ve el } \\
\text { tronco. }\end{array}$ \\
\hline
\end{tabular}

Sin embargo, esta alusión suele ser una imagen simplista, descontextualizada y aproblemática ( $\sin$ mostrar las relaciones entre ciencia y sociedad, ni las limitaciones del conocimiento científico actual). 
Por otra parte, también hemos encontrado anuncios que muestran imágenes explicativas. Esta función es ciertamente específica y exclusiva de la parte gráfica del mensaje, no encontrándonos situaciones equivalentes entre el componente de texto. Fundamentalmente, estas situaciones se dan en anuncios de clínicas-hospitales y de cosméticos (Tabla 7). La intención de explicar se hace a través del uso de fotografías reales o virtuales sobre las que se colocan elementos gráficos que dirigen la mirada, asocian, relacionan o destacan las partes de la imagen que recoge la información más destacada. Esta labor se lleva a cabo con flechas, líneas de trayectoria, transparencias, superposiciones de secuencias en movimiento, círculosrecuadros de aislamiento, uso de color, etc.

Tabla 7. Anuncios que utilizan imágenes explicativas

\begin{tabular}{|l|}
\hline \multicolumn{1}{|c|}{ Imagen en los anuncios de clínicas privadas } \\
\hline Imágenes virtuales de esqueleto, corazón y estructuras vistas con microscopio. \\
\hline Dibujo de una molécula de ADN. \\
\hline $\begin{array}{l}\text { Fotografía del torso de una mujer donde se ve una imagen virtual de un estómago con un balón en su } \\
\text { interior }\end{array}$ \\
\hline $\begin{array}{l}\text { Fotografías reales mostrando una paciente en una cama de la clínica y unas manos con guantes de } \\
\text { látex con una jeringuilla y algodón sobre la espalda de otra paciente. }\end{array}$ \\
\hline Dibujo de un estómago con un balón en su interior. Hombre con bata blanca y estetoscopio. \\
\hline Fotografías de profesionales y de equipos médicos. \\
\hline
\end{tabular}

\section{Conclusiones}

Del análisis de la estructura de los anuncios en prensa se pudo comprobar que resultaba adecuado para nuestros intereses dividir el mensaje en tres componentes. Así, se verificó que tanto el contenido como el estilo de los usos científicos variaban en función del elemento publicitario considerado. Por un lado se observó que la información que se encontraba en la letra pequeña, controlada legislativamente, resultaba homogénea, estable, bien definida y predecible, lo que implica que se puede anticipar con facilidad el tipo y el cómo se muestran estos contenidos. Aunque, obviamente, esta información muestra pequeñas diferencias en función del tipo de producto considerado. Por otro lado, las expresiones recogidas en el texto publicitario y las imágenes presentaban unos enfoques más dispares. Creemos que estas diferencias entre los distintos elementos de los anuncios nos deben hacer considerar el modo de enfocar su aplicación al aula.

Así, respecto a los términos detectados en el apartado letra pequeña encontramos que, al ser una información estandarizada y muy estable, resulta fácilmente categorizable (magnitudes, materiales, terminología especifica y procedimientos). Este hecho nos hace pensar en actividades orientadas a la detección, identificación, selección y agrupación de contenidos científicos. También se podrían utilizar estos contenidos publicitarios como referentes para introducirlos en el aula y contextualizar su uso (p.e., qué magnitudes podéis identificar, qué significan...; en qué circunstancias se utilizará este material...). En cualquier caso, se trata de acciones que no requieren una intervención sofisticada por parte del alumnado. Pero no sofisticada en el sentido de no necesitar un análisis, comprensión o interpretación del texto (Norris y Phillips, 2003), dado que se trata de términos aislados que no se estructuran gramaticalmente.

Por otra parte, el texto publicitario y las imágenes, aunque con aspectos en común entre ellos, presenta una variedad muy notable de contenidos y de enfoques, lo que implica la necesidad de llevar a cabo un trabajo de aula más centrado en el análisis crítico de las afirmaciones 
(Bartz, 2002), la reflexión sobre las imágenes transmitidas, la valoración sobre las intenciones subyacentes, etc. En cualquier caso, parece que si se quiere incorporar al aula estos componentes más vistosos, deben llevarse a cabo una adaptación específica. Siguiendo a Oliveras, Márquez y Sanmartí (2013), consideramos que no es suficiente con mostrar un texto en clase y preguntar sobre sus contenidos; pero estas cuestiones se escapan del análisis considerado aquí y quedan pendientes para futuros trabajos.

En cualquier caso, y para cualquiera de los elementos, los contenidos científicos que presentan los anuncios y el modo en que lo hacen, pueden - y deben - ser utilizados como un elemento más para determinar con qué ciencia interactúa la ciudadanía. En este sentido, como ya hemos relatado, multitud de autores y los preámbulos de los sucesivos currículos oficiales consideran que la educación debe tener, entre otras finalidades, la de dotar a los futuros ciudadanos y ciudadanas de herramientas que les permitan ser críticos sobre las decisiones que deben tomar. Parece evidente que este aspecto también debe implicar a la publicidad, de modo que los individuos conozcan las magnitudes y unidades utilizadas, sepan detectar un mensaje publicitario engañoso, sin sentido, exagerado o poco riguroso con la ciencia y la tecnología.

Pero la sociedad, los productos y las tendencias van cambiando a lo largo del tiempo. Debemos, por tanto, ser conscientes de la necesidad de actualizar nuestros conocimientos sobre los requerimientos formativos, los nuevos usos sociales y el efecto que el uso de la ciencia en la publicidad puede producir sobre los ciudadanos, tanto para el alumnado actualmente escolarizado como para los adultos ya fuera del sistema formativo. Un aspecto a destacar es precisamente la propia inclusión de la ciencia y la tecnología en la publicidad. Parece que, como indican los datos sobre las percepción social, se ha producido un aumento en el prestigio general de la ciencia y la tecnología en los últimos años, alcanzándose las cotas más altas de reputación; consecuentemente, se ha producido una intención por parte de la publicidad para legitimar, dar valor y reforzar sus afirmaciones con la utilización de la ciencia, no siempre de un modo adecuado.

En esta línea, se ha observado que ciertos usos inadecuados de la ciencia en la publicidad se han mantenido, mientras que otras acciones publicitarias han irrumpido en los últimos años Así, hemos podido recoger cómo se ha incrementado la tendencia a relacionar la bondad de un producto con lo ecológico, lo verde que es o lo cuidadoso que resulta con el medio ambiente, sin mostrar las razones de estas aseveraciones. Parece que el estudio muestra una cierta modificación en algunas preferencias publicitarias sobre la ciencia. Obviamente, estos cambios indican la existencia de vaivenes entre los temas sociocientíficos, o al menos en su tratamiento comercial. Por todo ello, consideramos que la publicidad se puede considerar como un indicador de las tendencias que reciben los individuos. Por tanto, los medios de comunicación y su publicidad resultan una fuente de la que extraer referentes que, queramos o no, afectan a nuestra ciudadanía, y parece pertinente su análisis desde el punto de vista de la Didáctica de las Ciencias Experimentales (Ezquerra, 2010; Díaz-Moreno y Jiménez-Liso, 2012). Sin embargo, es evidente que la publicidad, como parte del proceso de compra, es una actividad que se desarrolla a lo largo de toda la vida y, en este sentido, debe ser atendida por un aprendizaje a lo largo de todo este periodo; algo que parece muy lejano en estos momentos.

\section{Referencias bibliográficas}

Acevedo, J.A., Manassero, M.A. y Vázquez, A. (2002). Nuevos retos educativos: Hacia una orientación CTS de la alfabetización científica y tecnológica. Pensamiento Educativo, 30, pp. 1534. 
Acevedo, J.A. (2004). Reflexiones sobre las finalidades de la enseñanza de las ciencias: Educación científica para la ciudadanía. Revista Eureka sobre Enseñanza y Divulgación de las Ciencias, 1(1), pp. 3-16.

Acevedo, J.A., Vázquez, A. y Manassero, M.A. (2005). Más allá de la enseñanza de las ciencias para científicos: hacia una educación científica humanística. Revista Electrónica de Enseñanza de las Ciencias, 4(2).

APICE, (2007). Un punto de partida preocupante y difícil para la formación en ciencias. Alambique: Didáctica de las Ciencias Experimentales, 53, pp. 106-110.

Banet, E. (2007). Finalidades de la educación científica en secundaria: opinión del profesorado sobre la situación actual. Enseñanza de las Ciencias: Revista de Investigación y Experiencias Didácticas, 25(1), pp. 5-20.

Bartz, W.R. (2002). Teaching skepticism via the CRITIC acronym and the skeptical inquirer. The Skeptical Inquirer, 26(5), 42-44.

Bueno, E. (2004). Aprendiendo química en casa. Revista Eureka sobre Enseñanza y Divulgación de las Ciencias, 1(1), pp. 45-51.

Caamaño, (2007). El currículo de física y de química en la educación secundaria obligatoria en Inglaterra y Gales, Portugal, Francia y España. Alambique: Didáctica de las Ciencias Experimentales, 53.

Campanario, J.M., Moya, A. y Otero, J.C. (2001). Invocaciones y usos inadecuados de la ciencia en la publicidad. Enseñanza de las Ciencias: Revista de Investigación y Experiencias Didácticas, 19(1), pp. 45-56.

Díaz-Moreno, N. y Jiménez-Liso, M.R. (2012). Las controversias sociocientíficas: temáticas e importancia para la educación científica. Revista Eureka sobre Enseñanza y Divulgación de las Ciencias, 9(1), pp. 54-70.

Duggan, S. Y Gott, R. (2002), 'What sort of science education do we really need?' International Journal of Science Education, 24(7), pp. 661-679.

Esteban, S. y Pérez-Esteban, J. (2012).Estudiando el fenómeno de la radiactividad a través de noticias de prensa: el caso del espía ruso envenenado. Revista Eureka sobre Enseñanza y Divulgación de las Ciencias, 9(2), pp. 294-306.

EGM, (2012). Resumen Estudio General de Medios. Febrero a Noviembre de 2012 [En línea]: Consultado el 20 de diciembre de 2012 en la página web de La Asociación para la Investigación de los Medios de Comunicación (AMC).

Estudio Infoadex, 2013. Resumen Estudio Info Adex de inversión publicitaria en España 2013 [En línea]: consultado el 3 de julio de 2013 en la página web de Infoadex.

Ezquerra, A. (2003). ¿Podemos aprender ciencia con la televisión? Educatio Siglo XXI, n. 20-21, pp. 117-142.

Ezquerra, A., Fernández-Sánchez, B. Y Cabezas, M. (2013). Valoración de los conocimientos científicos implicados en el proceso de compra. Número extra IX Congreso Internacional sobre Investigación en Didáctica de las Ciencias, pp. 1165-1170.

Ezquerra, A. y Pro, A. (2006). Posibles usos didácticos de los espacios meteorológicos de la televisión. Revista Electrónica de Enseñanza de las Ciencias, 5(1), pp. 114-135.

Ezquerra, A. (2007). Sobre el efecto de los medios en la cultura científica. Revista Española de Física, 21(1), pp. 1-3. 
Ezquerra, A. (2010). Ciencias para el Mundo Contemporáneo y comunicación audiovisual. Alambique: Didáctica de las Ciencias Experimentales, 64, pp. 59-71.

Ezquerra, A. y Polo, A. (2010). Una exploración sobre la televisión y la ciencia que ve el alumnado. Revista Electrónica de Enseñanza de las Ciencias, 9(3), pp. 696-715.

FECYT, 2011. Percepción Social de la Ciencia y la Tecnología. Fundación Española para la Ciencia y la Tecnología, FECYT. Consultado el 3 de enero de 2013 en la página web del FECYT: http://www.fecyt.es/fecyt/docs/tmp/468797025.pdf

Fernández-Sánchez, B., Ezquerra, A. y Arillo, M.A. (2013). Ciencia a diario. Actas del II Congreso de Docentes de Ciencias de la Naturaleza. Jornadas sobre Investigación y Didáctica en ESO y Bachillerato. Madrid: Santillana.

Gallego, A. P. (2007). Imagen popular de la ciencia transmitida por los cómics. Revista Eureka sobre Enseñanza y Divulgación de las Ciencias, 4(1), pp. 141-151.

García Borrás, F.J. (2005). La serie C.S.I. como metáfora de algunas facetas del trabajo científico. Revista Eureka sobre Enseñanza y Divulgación de las Ciencias, 2(3), pp. 374-387.

García Borrás, F.J. (2008). House: otra forma de acercar el trabajo científico a nuestros alumnos. Revista Eureka sobre Enseñanza y Divulgación de las Ciencias, 5(2), pp. 212-228.

Gómez Crespo, M.A., Gutiérrez Julián, M.S. y Martín-Díaz, M.J. (2005). Un enfoque Ciencia, Tecnología, Sociedad para la Química del Bachillerato. El Proyecto Salters. Jornadas sobre la enseñanza de la Física y la Quimica. Nuevas tendencias en la enseñanza de la física y la química en la educación secundaria. Cosmo Caixa.

Halkia, K., y Mantzouridis, D. (2005). Students' views and attitudes towards the communication code used in press articles about science. International Journal of Science Education, 27(12), 13951411.

Harlen, W. (2001). The assessment of scientific literacy in the OECD/PISA project. Studies in Science Education, 36, pp. 79-104.

Hernández Sampieri, R., Carlos Fernández Collado, C. y Baptista Lucio, P. (2010). Metodología de la Investigación. México: McGraw-Hill. Interamericana Ediciones.

Hodson, D. (2003). Time for action: Science education for an alternative future. International Journal of Science Education, 25(6), pp. 645-670.

Hogan, K. (2002). Small groups' ecological reasoning while making an environmental management decision.Journal of Research in Science Teaching, 39(4), pp. 341-368.

Jarman, R. yMcclune, B. (2007). Developing scientific literacy. Using news media in the classroom. Maidenhead: McGraw-Hill International.

Jiménez-Liso, M.R., Torres, M., Salinas, F. y González, F. (2000). La utilización del concepto de pH en la publicidad y su relación con las ideas que manejan los alumnos: aplicaciones en el aula. Enseñanza de las Ciencias: Revista de Investigación y Experiencias Didácticas, 18(3), pp. 451-462.

Jiménez-Liso, M.R., Sánchez Guadix, A. y De Manuel, E. (2001). Aprender química de la vida cotidiana más allá de lo anecdótico. Alambique: Didáctica de las Ciencias Experimentales, 28, pp. 53-62.

Jiménez-Liso, M.R., Hernández, L. y Lapetina, J. (2010). Dificultades y propuestas para utilizar las noticias científicas de la prensa en el aula de ciencias. Revista Eureka sobre Enseñanza y Divulgación de las Ciencias, 7(1) pp. 107-126. 
Kolstø, S. D. (2006). Patterns in Students' Argumentation Confronted with a Risk-focused Socioscientific Issue. International Journal of Science Education, 28(14), pp. 1689-1716.

Lemke, J. (2006). Investigar para el futuro de la educación científica: nuevas formas de aprender, nuevas formas de vivir. Enseñanza de las Ciencias: Revista de Investigación y Experiencias Didácticas, 24(1), pp. 5-12.

Lewis, J. Y Leach, J. (2006). Discussion of Socio-scientific Issues: The role of science knowledge. International Journal of Science Education, 28(11), pp. 1267-1287.

Linn, M. C. (2002). Promover la educación científica a través de las tecnologías de la información y comunicación. Enseñanza de las Ciencias: Revista de Investigación y Experiencias Didácticas, 20(3), pp. 347-356.

López Nicolás, J.M. (2013). El lado oscuro de las bebidas energéticas [En línea]: Conferencia pronunciada el 6 de marzo de 2013 en Bizkaia Aretoa, Bilbao, en actividad organizada por la Cátedra de Cultura Científica de la UPV/EHU.

Marco-Stiefel, B., Ibáñez, T. y Albero, A. (2000). Diseño de Actividades para la Alfabetización Científica. Aplicaciones a la Educación Secundaria. Madrid:Narcea Ediciones.

Marco-Stiefel, B. (2007). Las fronteras de la Ciencia: Formación ciudadana en Secundaria. Madrid: Narcea Ediciones.

Más, C., Hernández, J., Solbes, J. y Vilches, A. (2007). La física y química en las enseñanzas mínimas de la enseñanza secundaria obligatoria en la LOE. Alambique: Didáctica de las Ciencias Experimentales, 15(53), pp. 47-58.

Medina I Cambrón, A., Sorribas Morales, C. y Ballano Macías, S. (2007). La publicidad y sus complejas relaciones con el discurso científico. Questiones publicitarias: revista internacional de comunicación y publicidad, (12), pp. 77-90.

Membiela, P. (2001). Algunas nuevas tendencias en el currículo de ciencias experimentales. En M. Martín Sánchez y J.G. Morcillo (Eds.), Reflexiones sobre la Didáctica de las Ciencias Experimentales. Madrid: Nivola, pp. 275- 281.

Membiela, P. (2002). Investigación-acción en el desarrollo de proyectos curriculares innovadores de Ciencias. Enseñanza de las Ciencias: Revista de Investigación y Experiencias Didácticas, 20(3), pp. 443-450.

Moreno Castro, C. (2006). Ingredientes mágicos y test clínicos en los anuncios como estrategias publicitarias. Comunicar: Revista Científica de Comunicación y Educación, 27(31), pp 123-128.

Norris, S.P., y Phillips, L.M. (2003). How literacy in its fundamental sense is central to scientificliteracy. Science Education, 87, 224-240.

Oliva, J.M. y Acevedo, J.A. (2005). La enseñanza de las ciencias en primaria y secundaria hoy. Algunas propuestas de futuro. Revista Eureka sobre Enseñanza y Divulgación de las Ciencias, 2(2), pp. 241-250.

Oliveras, B., Márquez, C. y Sanmartí, N. (2013). The use of newspaper articles as a tool to develop critical thinking in science clases. International Journal of Science Education,35 (6), 885-905

O'sullivan, T., Dutton, B. y Rayner, P. (1998). Studying the media: an introduction. London: Arnold.

Osuna, S. (2008). Publicidad y consumo en la adolescencia: La educación de la ciudadanía. Barcelona: Icaria Editorial, pp. 25-51. 
Paixão, F. (2004). Mezclas en la vida cotidiana. Una propuesta de enseñanza basada en una orientación ciencia tecnología y sociedad y en la resolución de situaciones problemáticas. Revista Eureka sobre Enseñanza y Divulgación de las Ciencias, 1(3), pp. 205-212.

Perales, F.J. y Vílchez, J.M. (2002). Teaching physics by means of cartoons: a qualitative study in secondary education. PhysicsEducation, 37(5), pp. 400-406.

Pozo, J.I. y Gómez Crespo, M. (1998). Aprender y Enseñar Ciencia. Madrid: Morata, pp. 33-51.

Pro, A., Y Ezquerra, Á. (2004). La enseñanza de la Física: Problemas clásicos que necesitan respuestas innovadoras. Alambique: Didáctica de las Ciencias Experimentales, 41, 54-67.

Pro, A. y Ezquerra Á. (2005). ¿Qué ciencia ve nuestra sociedad? Alambique: Didáctica de las Ciencias Experimentales, 43, pp. 37-48.

Programa Electoral IU-Los Verdes, 2011 [En línea]: Consultado el 6 de julio de 2013.

Programa Electoral PP, 2011 [En línea]: Consultado el 6 de julio e 2013 en la página web del Partido Popular.

Programa Electoral PSOE, 2011 [En línea]: Consultado el 6 de julio de 2013 en la página web del PSOE:

Programa Electoral UPyD, 2011 [En línea]: Consultado el 6 de julio de 2013 en la página web.

RD 1468/1988. Real Decreto 1468/1988, de 2 de diciembre, por el que se aprueba el Reglamento de etiquetado, presentación y publicidad de los productos industriales destinados a su venta directa a los consumidores y usuarios.

RD 1345/1991. Real Decreto 1345/1991, de 6 de septiembre, por el que se establece el Currículo de la Educación Secundaria Obligatoria.

RD 837/2002. Real Decreto 837/2002, de 2 de agosto, por el que se regula la información relativa al consumo de combustible y a las emisiones de CO2 de los turismos nuevos que se pongan a la venta o se ofrezcan en arrendamiento financiero en territorio español.

RD 1631/2006. Real Decreto 1631/2006, de 29 de diciembre, por el que se establecen las enseñanzas mínimas correspondientes a la Educación Secundaria Obligatoria.

RD 944/2010. Real Decreto 944/2010, de 23 de julio, por el que se modifica el Real Decreto 1599/1997, de 17 de octubre, sobre productos cosméticos para adaptarlo al Reglamento (CE) n. ${ }^{\circ}$ 1272/2008, del Parlamento Europeo y del Consejo, de 16 de diciembre de 2008, sobre clasificación, etiquetado y envasado de sustancias y mezclas.

Río, P.D. (1986). Publicidad y consumo, hacia un modelo educativo. Infancia y Aprendizaje: Journal for the Study of Education and Development, 35, pp. 139-174.

Tomás, A., y Hurtado, J. (2012). 38 escalones. Determinación de la potencia de una persona que sube escaleras. Alambique: Didáctica de las Ciencias Experimentales, 71, pp. 60-69.

Vázquez González, C. (2004). Reflexiones y ejemplos de situaciones didácticas para una adecuada contextualización de los contenidos científicos en el proceso de enseñanza. Revista Eureka sobre Enseñanza y Divulgación de las Ciencias, 1(3), pp. 214-223.

Vázquez, A. y Manassero, M. A. (2007). En defensa de las actitudes y emociones en la educación científica (I): evidencias y argumentos generales. Revista Eureka sobre Enseñanza y Divulgación de las Ciencias, 4(2), pp. 247-271.

Zeidler, D. L., Sadler, T. D., Simmons, M. L., y Howes, E. V. (2005). Beyond STS: A researchbased framework for socioscientific issues education. Science Education, 89(3), pp. 357-377. 